\title{
Conceptual Metaphor in Meditation Discourse: An Analysis of the Spiritual Perspective
}

\author{
Antonio-José Silvestre-López \\ asilvest@uji.es \\ Universitat Jaume I, Spain
}

\begin{abstract}
Meditation has spread beyond the frontiers of religion to go global in other areas of social practice, including secular and spiritual-but-not-religious contexts. Conceptual metaphor, as proposed by Lakoff (1993) has been described as a powerful mechanism to facilitate the communication of first-person experiences connected to religious and lay contemplative practice, including meditation and enlightenment, as reported in several studies. Despite the detachment of the spiritual-but-not-religious movement from other areas of practice, the question of how metaphor is used in discourse about meditation within this perspective has not been addressed. This paper investigates the role of conceptual metaphor in spiritual-but-notreligious meditation discourse through a bottom-up qualitative analysis of a corpus of talks about meditation given by three highly-recognized spiritual teachers. Results chart the topics that are addressed more frequently through metaphor in the corpus (metaphor target domains), describe the range of areas of experience (source domains) used to characterise metaphorically the three most frequent target domains (THOUGHT, THE PRESENT MOMENT, MEDITATOR), and discuss fundamental differences in non-deliberate and deliberate conceptual metaphor use with the help of a selection of examples from the corpus. The findings provide evidence of relevant metaphors used to model the experience and practice of meditation in spiritual-but-notreligious settings and how they are rendered in discourse. Comparisons with metaphorical models already identified in religious and secular discourse contexts are also established, with a special focus on the models that have been transferred from traditional religious meditation spheres to current contexts of social practice.
\end{abstract}

Keywords: Meditation; spirituality; discourse; metaphor; qualitative analysis

\section{INTRODUCTION}

Contemplative practices are ingrained in the great religions as a means to develop desirable attitudes for the individual and their community, to help them make progress on the spiritual path, or 'simply' to connect with the divine. Recently, meditation practices originally belonging to eastern religious traditions have expanded all over the world in a wide range of "nonreligious' areas (Albert \& Hernández, 2014; Campos \& Cebolla, 2016), which has come with a progressive disembedding from their original religious discourses. The 'religious-towardsnon-religious' turn, a social trend in which Asian religious practices are becoming decontextualised due to globalisation (Schedneck, 2013, p. 40), has paved the way for the development of several social spheres of meditation practice and, with them, different perspectives and discourses.

Some of these areas fall within the realm of spirituality, wherein the spiritual is conceived as separate from the religious (Fuller, 2001). This perspective, known as the spiritual-but-not-religious position, has become explicitly detached from all forms of institutionalised religions to approach more individualistic views of the sacred through processes of self-discovery to reach a deeper understanding of our own human nature and existence (Wong \& Vinsky, 2009). Since one of the outcomes of meditative practice is attaining 
a 'clear discernment' of reality, meditation has also found its way into this new perspective of spirituality (Cebolla, García-Campayo \& Demarzo, 2014). In these contexts, meditation is usually practised as a means of self-enquiry to connect with the inner self and to increase the practitioner's level of consciousness. The expansion of meditation in non-religious and nonspiritual disciplines has also become associated with the development of mindfulness abilities. Initially, mindfulness caught the attention of mental health professionals, and scientific reports attesting its benefits soon paved the way for its social expansion. Nowadays mindfulness meditation is widely accepted in general professional, educational and medical contexts (Campos \& Cebolla, 2016).

This interest in meditative practices has also reached the field of linguistics, where some studies have analysed the discourse of mindfulness practitioners in secular contexts, such as Silvestre-López (2016) and others who have tapped into religious spheres by studying the language used by Buddhist teachers to explain the fundamentals of meditation to the uninitiated (Silvestre-López, 2019; Silvestre-López \& Navarro, 2017). These studies highlight the importance of metaphor to facilitate understanding and communication about the abstract diversity of concepts and practices related to meditation. For example, studies focussing on Buddhist and Hindu religious discourse (Rajandran, 2017; Richardson \& Muller, 2019; Silvestre-López \& Navarro, 2017) emphasise the use of metaphorical source domains (SDs) related to the realms of nature (including bucolic landscapes and all sorts of creatures), light/darkness, and motion to refer to mental and emotional processes and spiritual development, including meditation and enlightenment. In contrast, the analysis of discourse in secular contexts has provided initial evidence of less 'vivid' or 'pictorial' metaphorical images to represent the experience (Silvestre-López, 2016), most of which qualify as superficial elaborations of the Event Structure Metaphor (Lakoff, 1993). Overall, these findings suggest that different ways of understanding meditation may be manifested in different ways of using metaphor in discourse.

Despite the detachment of the spiritual-but-not-religious movement from other areas of practice, the question of how metaphor is used in discourse about meditation within this perspective has not been addressed. Investigating metaphor use in this kind of discourse is significant because the particular evolution path of the spiritual-but-not-religious movement could be specified in potentially different discourse manifestations of similar metaphorical models, or in more innovative and context-specific uses of metaphor. This paper provides initial evidence of prominent metaphorical models (Lakoff, 1993) used to represent meditation in spiritual-but-not-religious settings by analysing the role of metaphor in the oral production of spiritual teachers in public talks about meditation. These findings contribute to the identification of convergence and divergence patterns of metaphor use across the different discourse settings, which can help to unveil how the practitioners' understanding of the experience is constructed in each setting.

\section{CONCEPTUAL METAPHORS IN THOUGHT, LANGUAGE AND COMMUNICATION}

In Conceptual Metaphor Theory (CMT) (Lakoff, 1993), a conceptual metaphor (CM) is a cognitive mechanism that allows one thing or area of experience that is usually more abstract, complex or unfamiliar (the Target Domain, TD hereafter) to be understood in terms of another that is more concrete, less complex or experientially closer to us (the SD). CMs are conceptual phenomena that materialise in language through metaphorical expressions. For example, the CM IDEAS ARE OBJECTS ${ }^{1}$ allows IDEAS (TD) to be structured in terms of a more concrete domain

\footnotetext{
${ }^{1}$ In this paper ' $\mathrm{CM}$ ' will be used to highlight the conceptual dimension of metaphor (associations between domains at the conceptual level). Reference to the domains involved in CMs will be made in small capitals (e.g. THOUGHT, EMOTION).
} 
(SD, PHYSICAL OBJECTS) and licenses expressions like I can't get this idea out of my mind (Lakoff, Espenson \& Schwartz, 1991, p. 94). But metaphors are not exclusively a matter of thought and language. Recent developments of CMT suggest that, in order to account for real metaphor use, CMT must incorporate the dimension of communication (Steen, 2011). Under this perspective (Steen, 2015), metaphors work as linguistic devices (dimension of language) and cognitive mechanisms (dimension of thought), but also as communicative tools used by speakers with a variety of social, discursive and communicative purposes (dimension of communication).

At the level of language, CMs are realised as metaphorical linguistic expressions that can be classified according to their textual/formal features as direct, indirect or implicit. In direct metaphors, the TD-SD connection is expressed directly in language (as in thoughts are like clouds floating in the sky), while in indirect metaphors the connection is not explicit. Finally, implicit metaphors account for cases where the metaphor vehicle establishes some sort of indirect grammatical or semantic connection with another metaphorical element, for example, a cohesive device like a pronoun referring to a noun used metaphorically earlier in a text.

At the level of thought, CMs can be classified according to their degree of conventionality or novelty (Steen, 2011). When a concept or topic is repeatedly used metaphorically by a linguistic community, figurative language becomes a well-established way of addressing it (e.g. let your thoughts pass by, don't go with them, as uttered by an instructor in a meditation session). In such cases, the metaphor is referred to as conventional. Novel metaphors, in contrast, establish fresh TD-SD associations; they introduce unusual ways of addressing a concept/topic figuratively and are therefore perceived as new or even creative in particular contexts of use (e.g. let your thoughts sail by, don't sail off with them) (Steen, 2015).

At the level of communication, metaphors are classified according to their communicative status as non-deliberate or deliberate (Steen, 2015). Non-deliberate metaphors (NDM hereafter) cover most realisations of CMs in discourse; they constitute typical ways (entrenched in language) in which people use metaphorical language to talk about a topic (e.g. albeit metaphorical, in is not likely to evoke the notion of CONTAINER in expressions like in pain or in time; just as expressions like it crossed my mind would not ordinarily make the addressee actively consider IDEAS/THOUGHTS as real OBJECTS moving through SPACE). However, language users may 'decide' to use metaphors deliberately. Deliberate metaphors (DMs hereafter) are discourse manifestations of CMs that are ostensively used as metaphors in communication between users. Steen (2015, p. 68) proposes that a metaphor is used deliberately "when its structure signals that the addressee has to move away their attention momentarily from the target domain of the utterance or even phrase to the source domain that is evoked by the metaphor-related expression".

Thus, DMs provide an external perspective from the topic of the utterance towards which the addressee's attention is drawn; in terms of TD-SD interaction, actively considering the SD is necessary for the adequate interpretation of what is being said about the TD. While this holds for DMs, it does not necessarily happen in NDMs (Reijnierse et al., 2018). This difference can easily be perceived in prototypical discourse realisations of each kind. For example, clear DMs instances are often manifested through novel direct or extended metaphors (i.e. metaphor realisations of fresh TD-SD correspondences at the level of thought in which the SD is explicitly signalled in language). In contrast, typical NDMs are cases of conventional metaphors realised linguistically as indirect or implicit metaphors. Compare, for example, the NDM expression of the IDEAS/THOUGHTS ARE OBJECTS CM in the example provided in the previous paragraph (it crossed my mind), with the DM realisation of the CM THOUGHTS ARE

'Metaphor' will be used as an umbrella term and more generally to refer to the manifestations of CMs in discourse at the linguistic (e.g. direct metaphor) and/or communicative levels (e.g. deliberate metaphor). 
SOAP BUBBLES in the example below, where ideas are explicitly elaborated as a particular kind of 'object': in meditation, thoughts can be seen as soap bubbles: you may feel tempted to chase them, but if you just watch them, you will realise that they arise, stay for a while, and eventually vanish in the space of your mind. Nevertheless, most realisations of CM in discourse are not prototypical and easily-identifiable cases. For example, conventional metaphors can also be used deliberately, many DM instances are not signalled in discourse, and their deliberate status is often grounded in topic or even genre incongruity (Cf. Reijnierse, 2017). Consequently, it is not always possible (nor methodologically advisable) to determine deliberateness/nondeliberateness based on intuition. In order to reliably identify all potential DM uses in discourse, the Deliberate Metaphor Identification Procedure (DMIP) has recently been proposed (cf. Reijnierse, 2017; Reijnierse et al., 2018; and the method section in this paper for further details).

Using metaphors deliberately can be useful in various respects. It can help the speaker to put their points across more efficiently and better reach their audience by adding the perspective of an external SD that sets a common ground upon which speaker and audience can (re)consider certain aspects of the topic at hand. For instance, when addressing a non-expert audience, meditation teachers strive to get rid of general misconceptions about meditation (e.g. meditating is leaving the mind blank) while also trying to replace erroneous models with more accurate representations of what meditation is really about (e.g. meditating is not leaving the mind blank, but becoming aware all phenomena of experience without intervening). The use of metaphor is very convenient in this respect, as introducing a more tangible SD allows teachers to offer more appropriate explanations while also affording processes of reframing (Bogetić, 2017) and reconceptualisation (Goatly, 2011) (e.g. helping the audience to see a topic like 'meditation' in a new light). Moreover, explicitly bringing in an external area of experience that is experientially closer to the audience (e.g. the SD SKY in the example below) lets speakers craft more suitable, ad-hoc examples to facilitate the understanding of unfamiliar concepts or procedures (e.g. the nature of the TD MEDITATOR and their relationship with thoughts) by highlighting common TD-SD aspects (e.g. the meditator is the space for thoughts to happen, just like the vast sky is the space for clouds to form, come, go and dissolve; in meditation one must learn to observe those clouds in our inner sky: how they arise, move around and dissolve).

\section{AIM}

This paper addresses the use of $\mathrm{CM}$ in meditation discourse framed within a spiritual perspective by analysing the oral production of three spiritual teachers in a selection of talks about meditation. Specifically, it aims to reveal the most representative CMs in the corpus (conceptual dimension) by identifying and analysing their verbal manifestations in discourse (linguistic dimension). Due to the pedagogical nature of the talks, some communicative value is assumed to hold for at least part of the metaphors used therein. Thus, the study is also sensitive to the communicative dimension by distinguishing between non-deliberate and deliberate use.

\section{METHOD}

The corpus compiles open talks recorded on video where each spiritual teacher addresses the notion of meditation: a public talk given by Jiddu Krishnamurti (Krishnamurti, 2012), a talk by Eckhart Tolle in one of his public seminars (Tolle, 2009), and an open talk series about meditation by Jeff Foster (Foster, 2012-2016). This selection is the result of applying homogeneity criteria concerning talk topic, purpose and intended audience, and speaker's profile. Topic, purpose and audience homogeneity criteria reduce the choice of eligible talks to those whose subject matter is meditation and whose common purpose is explaining some of 
its most fundamental aspects to the general public. Speaker's profile homogeneity restricts speaker's choice in terms of: (i) similar perspectives about the topic; (ii) being highly recognised and influential English-speaking spiritual authors in modern western society; and (iii) not being directly connected to any religion, but associated with the modern view of spirituality mentioned in the introduction. All talks were delivered in spontaneous English and are original by the authors. The oral production of the speakers was transcribed to build a corpus that amounts to 18,989 words. The corpus is purposefully small to allow for an inductive coding approach that facilitates the discovery of all possible types of metaphor. Moreover, the bottom-up qualitative approach adopted here also favours the adequate application of DMIP (Reijnierse et al., 2018).

The analysis runs through three stages: identification, codification and reconstruction. Metaphor identification was carried out by applying DMIP which draws on the Metaphor Identification Procedure Vrije Universiteit (MIPVU) (Steen et al., 2010) as an initial step to identify linguistic realisations of CMs in discourse. Then it establishes a procedure to determine whether these metaphor-related words (MRWs) are used deliberately by taking into account the role of context and utterance meaning. According to DMIP, a MRW is regarded as potentially deliberate if the SD it evokes is needed to explain the referential meaning of the utterance where it appears. In order to identify the presence of the SD as part of the referential meaning, a series of linguistic signals, co-textual and contextual cues are used (cf. Reijnierse, 2017; Reijnierse et al., 2018). ${ }^{2}$

Metaphor codification was performed with the qualitative data analysis software ATLAS.ti. The model proposed by Kimmel (2012) was adopted as a departure point for the analysis, with particular adaptations to include the communicative dimension (the application of DMIP and the coding of DMs). ATLAS.ti facilitates qualitative analysis through a system of quotations (stretches of relevant text selected from the corpus) and code units (analytical categories like TDs, SDs or DM uses) that can be created and assigned to quotations as required by the flow of the inductive analysis. In order to do the coding, once a unit was identified as metaphorical and its nature was determined by DMIP, a quotation was generated and an appropriate TD, SD, and DM/NDM code was applied (see below), e.g. TD_THOUGHT, SD_OBSTACLE, MET_Deliberate. For the purposes of this study, each quotation is used to mark a stretch of text that encompasses linguistic realisations of a single CM. One or more MRWs may be gathered within the same quotation, provided that they all (i) belong to the same TDSD pairing and (ii) show the same 'communicative use' (deliberate or non-deliberate). Thus, for example, in cases of extended metaphors where DMIP identified several MRWs as potentially deliberate, a single quotation was used to account for the underlying CM, provided that the criteria above were met.

A compositional coding strategy (cf. Kimmel, 2012, p. 13-15) was adopted by which the TDs and SDs identified in each quotation were coded separately. Deliberate/non-deliberate uses were also assigned a separate code (MET_Deliberate, MET_Non-deliberate). Coding such elements separately for each quotation -as opposed to, say, coding a full CM (e.g. CM_THOUGHT_IS_OBSTACLE) - allowed code correspondences and frequencies (TD, SD, deliberate/non-deliberate uses), as well as quotation contents (expressions) to be retrieved in an orderly way in the metaphor reconstruction stage (see below). During the coding stage, the ATLAS.ti book of TD and SD codes grew inductively as the coding process developed until a saturation point was reached, that is, a point where no more TD or SD codes were needed to categorise new corpus examples (cf. Kimmel, 2012, p. 19-20). Throughout the process, in

\footnotetext{
${ }^{2}$ For a detailed account of the steps followed to apply DMIP, see Reijnierse et al. (2018, p.: 135-137). Reijnierse (2017) also offers a thorough description of how DMIP works with different types of DM realisations across discourse and register typologies. For a description of the steps involved in the application of MIPVU (the initial step of DMIP), see Steen et al. (2010, pp. 25-42).
} 
order to determine the level of TD and SD generalisation that best adheres to metaphor use in the corpus, TD and SD codes were restructured several times so that the code labels would fit all and only the metaphorical expressions in each code (cf. Bogetić, 2019). This process of reconfiguration is necessary in most bottom-up analyses, and is facilitated by ATLAS.ti by means of commands that allow researchers to 'fuse' codes into higher-order (i.e. more general) code categories or to 'split' codes into finer-grained (more specific) categories. For example, at an early coding stage, no 'past-present-future' distinction was considered regarding the metaphorical characterisation of time in the corpus; consequently, all 'time' metaphors were initially coded under a unique TD code (TD_TIME). However, as the analysis developed, it became apparent that, throughout their talks, the speakers make an explicit distinction between the present moment, the future and the past, where the present moment is considered as the only 'real' moment, and the future and the past are described as projections existing only in our minds. This motivated the decision of splitting the original code 'TD_TIME' into three finer-grained separate codes adhering more closely to the conceptual distinction made in the corpus (TD_TIME: THE PRESENT MOMENT, TD_TIME: THE FUTURE, and TD_TIME: THE PAST). This involved a revision of all metaphor instances coded up to that moment with the original TD_TIME to guarantee their correct rearrangement in each of these newly-created code categories. This process was followed in all cases of code reconfiguration involved in the analysis.

Finally, the metaphor reconstruction stage involved retrieving TD-SD correspondences in order to reconstruct the most relevant CMs and their expressions in the corpus. The ATLAS.ti code manager and query tool were used to retrieve the most frequent TDs, to gather the SDs combining with each TD, to reveal the distribution of deliberate and non-deliberate uses for each TD-SD set, and to retrieve examples (via quotation contents) of such uses in the corpus.

\section{RESULTS AND DISCUSSION}

To provide insight into the use of metaphor in this type of meditation discourse following a bottom-up approach, it is first necessary to consider the topics that are addressed more frequently through metaphor in the corpus, and then explore the CMs underlying the most significant topics. Table 1 presents the most frequent TDs in the corpus. These appear as ATLAS.ti TD codes arranged by frequency (number of quotations in which a code is used). A total of 28 TDs were coded, but only the most frequent ones down to 5 metaphor instances are presented here.

TABLE 1. Main TDs in the corpus

\begin{tabular}{lc}
\hline Target domain & Frequency \\
\hline TD_THOUGHT IS... & 64 \\
TD_TIME: THE PRESENT MOMENT IS... & 60 \\
TD_PERSON: MEDITATOR IS... & 57 \\
TD_LIFE IS... & 30 \\
TD_MEDITATION IS... & 25 \\
TD_FEELINGS ARE... & 21 \\
TD_EMOTIONS ARE... & 20 \\
TD_PREVIOUS EXPERIENCE IS... & 20 \\
TD_CONSCIOUSNESS IS... & 17 \\
TD_THE MIND IS... & 14 \\
TD_TIME: THE FUTURE IS... & 12 \\
TD_FORM (MATTER) IS... & 10 \\
TD_TIME: THE PAST IS... & 10 \\
TD_PERSON: PEOPLE (GENERAL USE) ARE... & 7
\end{tabular}




\begin{tabular}{ll} 
TD_ACCEPTANCE IS... & 5 \\
TD_REJECTION IS... & 5 \\
TD_SENSATIONS ARE... & 5 \\
\hline
\end{tabular}

The topics covered in contemplative talk are usually abstract, and those found in the corpus are no exception to the rule. The bulk of topics qualifying as TDs refer to central notions in the talks like MEDITATION and the MEDITATOR, to mental phenomena or cognitive processes (e.g. THOUGHT, PREVIOUS EXPERIENCE, CONSCIOUSNESS, MIND), to the realm of feeling, emotion and affect (e.g. FEELINGS, EMOTIONS), or to other general -but still abstract- topics like everyday life (LIFE) or the conception of time (THE PRESENT MOMENT, THE FUTURE, THE PAST). Among all topics raised in the corpus, THOUGHT, THE PRESENT MOMENT and MEDITATOR are expressed metaphorically with considerable frequency (over 50 times), and can be regarded as the three most significant TDs. The following sections describe the metaphorical models used to characterise THOUGHT, THE PRESENT MOMENT and MEDITATOR respectively. ${ }^{3}$ Each section introduces a table displaying the combinations of the TD with a set of SDs, together with metaphor counts for non-deliberate and deliberate uses. A report on the most relevant TD-SD combinations follows each table, where the most representative discourse realisations of these TD-SD pairings are discussed and illustrated with NDM and DM examples.

\section{THOUGHT METAPHORS}

Being able to identify and manage our mental contents is as useful in meditation as in everyday life. Thoughts are the mental contents par excellence, and a common topic in meditation talk. This is reflected in the corpus, where the TD THOUGHT is characterised metaphorically on 64 occasions, both non-deliberately $(\mathrm{N}=53)$ and deliberately $(\mathrm{N}=11)$, each of them evoking one of the 3 SDs displayed in Table 2.

TABLE 2. THOUght CMs in the corpus: TD-SD pairings and non-deliberate/deliberate uses

\begin{tabular}{llccc}
\hline Target domain & Source domains (codes) & $\begin{array}{c}\text { Total } \\
\text { counts }\end{array}$ & $\begin{array}{c}\text { Non- } \\
\text { deliberate } \\
\text { metaphors }\end{array}$ & $\begin{array}{c}\text { Deliberate } \\
\text { metaphors }\end{array}$ \\
\hline & SD_PERSON (personification) & 32 & 27 & 5 \\
TD_THOUGHT IS... & SD_OBJECT (objectification) & 28 & 26 & 2 \\
& SD_SPACE_OR_PLACE: NATURAL SPACE - & & & \\
& MASS OF WATER (ELEMENT) & 4 & 0 & 4 \\
\hline
\end{tabular}

Personification and objectification (reification) are the most frequent cases of metaphorical characterisation of the TD THOUGHT ( $\mathrm{N}=60 / 64$ altogether $)^{4}$ in the corpus. These cases are instantiations of the higher-order CM ABSTRACT NOTIONS ARE PHYSICAL ENTITIES and, as such, are commonly realised in discourse through conventional ontological metaphors (Lakoff, 1993), most of which belong to non-deliberate uses. Deliberation, nonetheless, is present in some uses, which made it possible to unveil a pattern in the corpus concerning the degree of granularity -how much conceptual content of a given domain is selected and elaborated in discourse (Langacker, 2008)- with which SDs are rendered through NDMs and DMs. When CMs like THOUGHT IS A PERSON or THOUGHT IS AN OBJECT are used nondeliberately, the kind of 'person' or 'object' is seldom specified or even referred to in the sentential context (these are often indirect realisations of the $\mathrm{CM}$ at the linguistic level), as in examples 1 and 2 below. In contrast, in the fewer cases in which personifications or objectifications are used deliberately, the SD is construed in more detail; it is often presented

\footnotetext{
${ }^{3}$ Due to space constraints, it is not possible to analyse all CMs underlying every TD in the corpus.

${ }^{4}$ That is, altogether, personification and objectification amount to 60 metaphor instances out of the total number of realisations in the corpus (64).
} 
as a defined, easily identifiable entity (e.g. a particular exemplar of a concrete entity the addressee can almost picture vividly in their mind) and/or is formally present in the sentence where the metaphorical expression appears (e.g. as a direct metaphor realised linguistically via explicit comparison devices), as in examples 3 and 4.

(1) And then thought comes in and tries to accept, or tries to reject-actually it's the same thing really... (Foster, 2012, January 26, 9:23)

(2) What you are is just the capacity for thoughts, sensations, feelings, sound... So the invitation is just to notice thoughts coming and going, and to recognise yourself in that noticing as the capacity for thoughts. (Foster, 2012, May 24, 5:25)

(3) If you conceive of a thought or a feeling as a child standing in the doorway -the doorway of presence, the doorway of the present moment- and that child could be a thought, a feeling, it could be sadness, it could be fear... So what we normally do is "slam the door in the face of that child" and say "I don't want you here, you shouldn't be here in the present moment, there's no room for you". (Foster, 2016, May 19, 1:50)

(4) So the world, which is the world of things, which includes thoughts -because every thought is an object, it has a form, a thought form- the world of things, including your mind, no longer has the power to draw you in completely. (Tolle, 2009, 28:12)

Example 1 illustrates a conventional case of personification where thoughts are presented as entities with their own intellectual perspectives on the practice of meditation or perform actions that are typically attributable to human beings. In it, the meditator is meditating, but it is thought that 'kicks in' and starts judging present moment experience by accepting or rejecting it. When thoughts are characterised as objects, as in example 2, they are portrayed as coming and going, arising and dissolving in the meditator's field of consciousness. Neither 1 nor 2 specify the nature of such 'persons' or 'objects'. In contrast, examples 3 and 4 introduce less conventional and far more elaborated SDs. When THOUGHT IS A PERSON is used deliberately, it typically conveys some illustrative purpose (e.g. to exemplify facets of thoughts we seldom pay attention to) or becomes an aid to reconceptualise our experience and develop more appropriate attitudes towards them. In such cases, the 'kind of person' is fully specified and often set in a detailed scenario. Example 3 elaborates, via a direct extended metaphor, a fine-grained metaphorical scenario, that of a house we own, where thoughts are presented as 'children at the door' asking to come in. Foster's use of the HOUSE scenario can be traced back to one of his 2012 talks (January 26) with similar communicative purposes (developing understanding of acceptance, see example 8). The model seems to draw on The guest house poem by the $13^{\text {th }}$-century Sufi poet Rumi, which pictures the human being as a guest house for emotional and mental experience. In this case, Foster's HOUSE scenario pictures present moment experience as a house the meditator owns, and all sorts of mental contents and emotional events as visitors that are looking for shelter and should be allowed in without resistance (particularly, unwelcome guests are seen as opportunities to develop acceptance). In his 2016 talk (May 19), Foster reintroduces the model as described in example 3, and uses it deliberately again later in the same talk. Foster's 2016 production echoes Rumi's poetic metaphor, but Foster slightly modifies participants' roles by picturing thoughts as children and the meditator as an ill-mannered adult. This SD elaboration allows him to bring forth a powerful image intended to evoke first-hand experiences of compassion and acceptance in the audience, and then to transfer the same feeling and affect to potentially unwanted thoughts, feelings or emotions. The metaphor is thus masterfully recontextualised (Semino et al., 2013) to facilitate acceptance through reconceptualisation, but also by evoking first-person affective and attitudinal components which might have been more difficult to convey through literal language (Cf. Cameron \& Deignan, 2006, p. 676). In example 4, the conventional CM 
THOUGHT IS AN OBJECT is revisited by Tolle, who explicitly declares thoughts as objects using a direct metaphor formula (A IS B). It is noteworthy that, while uttering 'because every thought is an object, it has a form, a thought form', Tolle gestures the form of a physical object around his head, hence strengthening the metaphorical connection. This invites the audience to reconsider thoughts as entities with formal properties (the SD becomes momentarily the focus of attention), which revitalises the metaphor and allows him to artfully merge inner and outer spaces (the world of mental contents and the world of physical things) in a single and unique space, a central idea in his talks (see next section).

Example 4 is a prototypical deliberate elaboration of THOUGHT IS AN OBJECT, but thoughts can be portrayed in more creative ways; for example, some metaphorical models in the corpus depict the TD MEDITATOR as a vast body or mass of water, like the ocean or a lake (see 'MEDITATOR metaphors' section). In the book of SD codes, this is labelled 'SD_SPACE_OR_PLACE: NATURAL_SPACE-MASS_OF_WATER'. If the meditator is framed as a MASS OF WATER, thoughts may be addressed as particular 'elements' in it (e.g. waves in the ocean). When these models are used in discourse, they evoke conceptually rich scenarios that are often rendered with DMs. The code 'SD_SPACE_OR_PLACE: NATURAL_SPACEMASS_OF_WATER_(ELEMENT)' in Table 2 refers to a CM that is in fact realised exclusively deliberately in the corpus $(\mathrm{N}=4)$. THOUGHT IS A WAVE, widely used in Buddhist meditation discourse (Silvestre-López \& Navarro, 2017), is reused several times in Foster's production; and in examples like 5, it allows him to evoke a vivid image to emphasise the dimensions of inseparability and acceptance in the relationship between thinker and thought.

(5) They [thoughts] may ultimately not define what I am, but what I am at the same time is inseparable from thoughts. It allows thoughts. It gives permission, you could say, for thoughts to come and go. So, thoughts are deeply allowed in what I am, just as every wave is deeply allowed in the ocean. (Foster, 2012, May 24, 6:35)

Overall, and as compared to other TD models (see below), the metaphorical characterisation of THOUGHT in the corpus shows very low SD diversity, with CMs being condensed mainly in two SDs that allow THOUGHT to be endowed with more tangible characteristics. Taking THOUGHT CMs as a whole, a correlation can be drawn between the dimensions of thought and communication: non-deliberate uses are most frequently realised through conventional ontological metaphors that may be present in most cultures and discourse areas. In contrast, deliberate realisations seem to portray THOUGHT in relatively creative ways, sometimes recalling 'classical' images that may be harder to find in general discourse, but that can be traced back to religious contemplative contexts like Buddhism (THOUGHTS ARE WAVES IN THE OCEAN) and Islamic mysticism (THOUGHTS ARE GUESTS IN A HOUSE).

Thoughts have the power to spark emotions, trigger further thoughts, drive our behaviour and change our mental and physiological state (Cebolla et al., 2014); consequently, learning to deal with them by training our attention and cultivating the appropriate attitude towards them is one of the first things to be learnt in meditation. By and large, the set of CMs about THOUGHT used by the three speakers in their talks are revealed as an aid in this teaching.

\section{THE PRESENT MOMENT METAPHORS}

In most contemplative traditions and modern meditation paradigms, attention training is a prerequisite to settle the mind and develop advanced meditative skills (Dahl et al., 2015). One of the most widespread attentional practices involves becoming consciously aware of present moment experience by paying attention to how our inner and outer experience unfolds, with acceptance and without judging it or reacting to it (Kabat-Zinn, 2003). The present moment is 
thus a particularly important concept in early meditation stages, and 'learning to be in the now' is a recurrent topic in lay meditation discourse contexts (Silvestre-López, 2016). In terms of metaphors, THE PRESENT MOMENT is also an important topic in the talks analysed here, ranking as the second most prolific TD in the corpus (see Table 1), with 60 instances of NDMs (N=44) and DMs ( $\mathrm{N}=16)$ distributed across 11 different SDs (see Table 3).

TABLE 3. The PRESEnt Moment CMs: TD-SD pairings and non-deliberate/deliberate uses

\begin{tabular}{llccc}
\hline & & $\begin{array}{c}\text { Non- } \\
\text { Target domain }\end{array}$ & $\begin{array}{c}\text { Total } \\
\text { counts } \\
\text { deliberate } \\
\text { metaphors }\end{array}$ & $\begin{array}{c}\text { Deliberate } \\
\text { metaphors }\end{array}$ \\
\hline & Source domains (codes) & & & \\
& (UNDEFINED SPACE) & 22 & 20 & 2 \\
& SD_PERSON (personification) & 18 & 15 & 3 \\
& SD_CONFINEMENT MEANS AND OPPRESSIVE & & & \\
& STRUCTURES & 6 & 6 & 0 \\
TD_TIME: THE & SD_STILLNESS & 3 & 1 & 2 \\
PRESENT & SD_SPACE_OR_PLACE: SHELTER (HOUSE AND & & & 2 \\
MOMENT IS... & SD_TOOL/MEANS TO AN END & 2 & 0 & 2 \\
& SD_SPECTACLE (SHOW, MOVIE, DANCE...) & 2 & 0 & 2 \\
& SD_VALUABLE RESOURCES & 2 & 0 & 0 \\
& SD_OBSTACLES & 1 & 0 & 1 \\
& SD_LIFE & 1 & 0 & 1 \\
& SD_SPACE_OR_PLACE: NATURAL SPACE - & & & \\
& MASS OF WATER & 1 & 0 & 1 \\
\hline
\end{tabular}

The present moment is configured here as a 'space' (purportedly the only real one) where all phenomena can be experienced to take place or exist. This includes our bodies and physical reality, but also any kind of mental projections like the future and the past, as well as thoughts about the future and the past. This space is represented metaphorically in the corpus with different degrees of refinement. As displayed in Table 3, the most prolific CM is THE PRESENT MOMENT IS SPACIOUSNESS, which includes conventional TIME-IS-SPACE metaphors realised non-deliberately $(\mathrm{N}=20)$ as in example 6 , as well as -much less frequent- deliberate uses $(\mathrm{N}=2)$ in which the present moment is described as the space (a place) where anything can be found to happen, as in 7 below.

(6) So, observation can only take place in the now, in the very doing of it: when you are angry, when you are greedy... to observe it as it is. (Krishnamurti, 2012, March 2, 15:06)

(7) You're missing something -not some "thing"- you're missing that which is concealed underneath the form that this moment takes. And that's easy to do, and that's a great deception that most humans are subject to. What they are looking for in some future moment is already here, hiding in the most unlikely place called the present moment. (Tolle, 2009, 42:07)

When realised deliberately, this sort of undefined space is set as at least two more kinds of 'places', namely, as a HOUSE (in this case activating the scenario set in example 3 ) and as a MASS OF WATER (an ocean in which all experienced phenomena are characterised as waves). Example 8 exemplifies both scenarios through mixed metaphor.

(8) ... we want to stand at the gate of present experience. We want to say: "Yes, this wave is allowed in, and this wave is not allowed in". So we want to say: "Oh yes: happiness, you can come in, and sadness, you're not allowed in", or "joy, you're allowed to come in, [...] discomfort you're not allowed in". It's like we want to... we try so desperately to be in 
control, to be "wave managers", you could say. We try to be wave managers. (Foster, 2012, January 26, 14:05)

Physical reality is in the present moment, but our minds have a tendency to drift away from it back to the past or forth to the future. This is necessary for our survival, but excessive rumination or anticipation (including our eagerness to attain goals or reach future stages in our life) may lead to negation of the present moment, up to the point that we can come to perceive it as something negative, like an OPPRESSIVE STRUCTURE we want to escape from (as in 9) or an OBSTACLE in our way, as in 10 below.

(9) That's where suffering begins. Suffering is in our attempt to escape this moment, and we attempt to escape this moment... (Foster, January 26, 12:45)

(10) The delusion that the present moment is some kind of obstacle to where I really want to go or be. And it's very common; it's so widespread that it dominates many people's lives entirely: the delusion that the present moment is some kind of obstacle in my way. (Tolle, 2009, 29:52)

Axiologically opposed views regarding present moment experience seem to govern a choice of affectively positive and negative SDs in the discourse of the spiritual teachers. In the corpus, positive-to-neutral SDs (the scenarios activated in 8, but also other SDs like STILLNESS or VALUABLE RESOURCE, see Table 3) are used to address THE PRESENT MOMENT from the 'correct' perspective, that is, a meditator's view of reality involving effortless acceptance of all kinds of experience. On the contrary, when allusion is made to an attitude of rejection of THE PRESENT MOMENT, SDs evoking impediments to progress are brought forth. This view coincides with the 'default' or non-meditative perspective that the spiritual teachers want their audience to get rid of; for them, it is a misconception of the present moment, a 'deluded' view of reality (10) that inevitably engenders suffering (9).

Apart from CMs that portray the present moment as space, the second most important metaphorical model in the corpus is THE PRESENT MOMENT IS A PERSON. Unlike in the case of the TD THOUGHT, the corpus shows a balanced distribution of NDM $(\mathrm{N}=15)$ and DM $(\mathrm{N}=13)$ realisations which the spiritual teachers use systematically to tackle acceptance and rejection by characterising the present moment as a person we can talk to (this is usually realised nondeliberately, as in example 11), or as an enemy we should try to befriend, as in 12 .

(11) If it's appearing in present experience, [then] what you are has already said "yes" to it. What you are has already said "yes" to what's appearing presently. (Foster, January 26, 4:38)

(12) So, here [the point is] becoming friendly with the present moment, and stop treating it as an enemy, or run away from it... (Tolle, 2009, 33:47)

THE PRESENT MOMENT is an important metaphorical topic in the corpus due to the high number of non-deliberate uses (most of them covered by the SPACIOUSNESS and PERSONIFICATION SDs). However, it is also worth noting that 16 instances are a considerable number of DMs, and the fact that they are distributed across 9 out of a total of 11 SDs is indicative of the wealth of nuances with which this topic is characterised metaphorically in discourse. This is most probably due to the efforts the spiritual teachers make in their talks to reach their audience and have them understand the importance of the present moment. Likewise, it is also worth noting that, in contrast to high-frequency realisations of NDMs, most of the SDs used as metaphors fewer than three times in the corpus are also realised exclusively 
deliberately, which also accounts for the overall singularity of the scenes created in deliberate uses.

\section{MEDITATOR METAPHORS}

SD diversity is also especially descriptive of MEDITATOR, the TD combining with the widest range of SDs in the corpus. As displayed in Table 4, TD_ MEDITATOR was found to pair with 16 different SDs to yield a total of 57 instances. But the case of MEDITATOR is also remarkable because on most occasions $(\mathrm{N}=54)$ these $\mathrm{CMs}$ are realised deliberately in discourse. In fact, deliberateness pervades all MEDITATOR CMs in the corpus (all SDs in Table 4 display at least one $\mathrm{DM})$, whereas non-deliberate uses $(\mathrm{N}=3)$ agglutinate in a single $\mathrm{SD}$.

TABLE 4. MEDITATOR CMs: TD-SD pairings and non-deliberate/deliberate uses

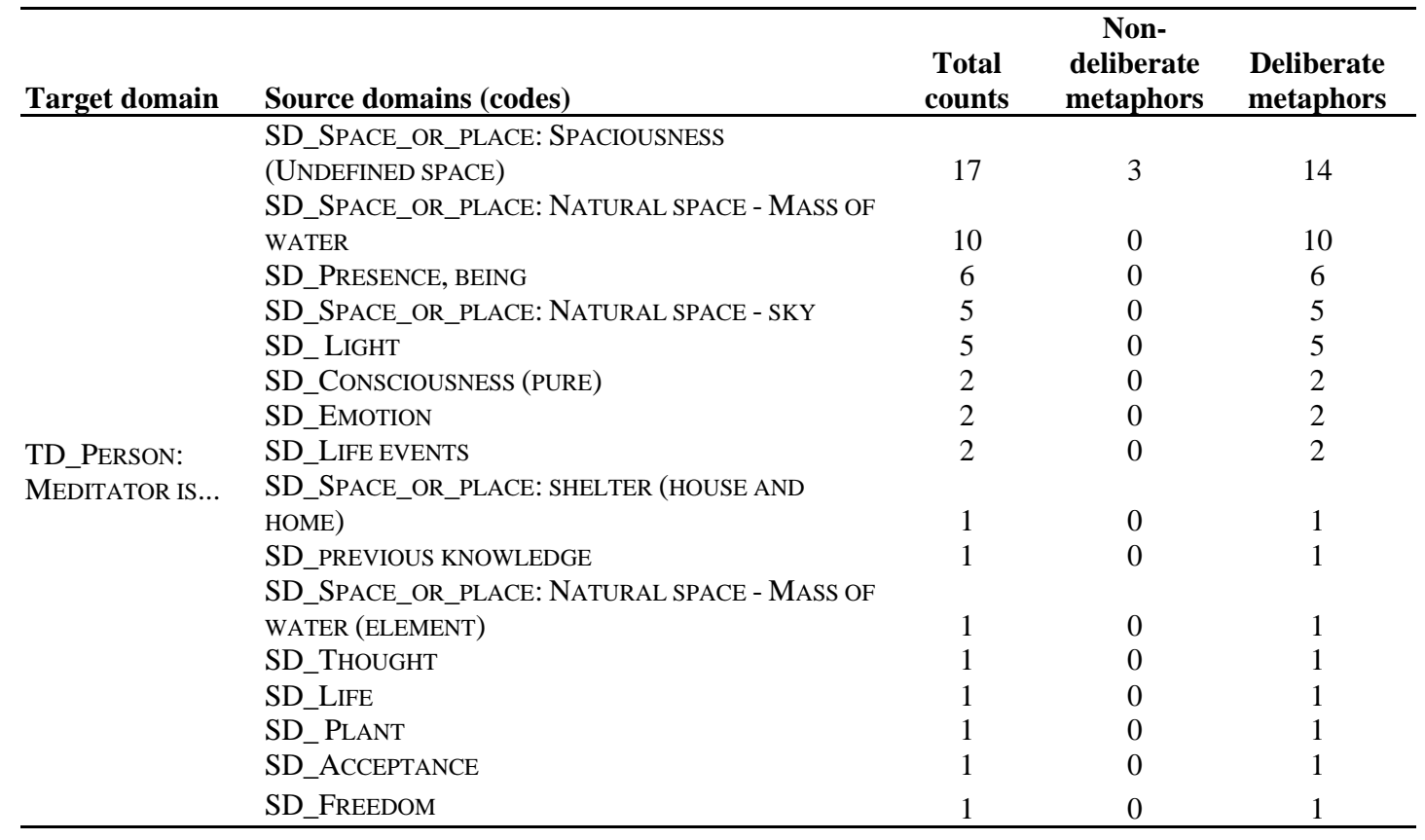

These instances of NDM belong to MEDITATOR IS SPACIOUSNESS. The CM applies to the TD MEDITATOR but it clearly inherits its structure from the higher-level conventional CM PEOPLE ARE CONTAINERS (Lakoff et al., 1991), as its realisations in discourse present the meditator as the space in which thoughts, feelings or emotions arise and exist, a space which can also be 'emptied' with practice (see 13 and 14 below). These non-deliberate uses belong to conventionalised ways in which we use language to communicate about mental or emotional 'contents' (e.g. thoughts or emotions that 'we have'). Deliberate uses also draw on conventional metaphors and thus exploit the same logic, but they profile instead the 'spaciousness' component by stating it explicitly in discourse, often through direct metaphor realisations that extend beyond the sentence level, like the one in example 15 .

(13) So, the moment you're trying to release or let go of a thought or feeling, basically you're in deep resistance to that thought or feeling. You don't want it within you. (Foster, 2016, May 19, 2:34)

(14) Do you understand? This is real meditation: to start from the very beginning [by] not knowing -please if you start with knowing you end up in doubt. [...] We began by saying we must investigate into ourselves, and ourselves is the known, therefore, empty the 
known. So from that emptiness all the rest of it flows naturally. (Krishnamurti, 2012, March 2, 68:30)

(15) So, you can see how what you are doesn't actually do meditation. You could say what you are is not the meditator. What you are is this wide open space in which all thoughts, all sensations, all feelings, all images, everything, the entire world is allowed, deeply allowed to arise and dissolve. You could say that what you are doesn't do meditation, but what you are is the space of meditation. (Foster, 2012, May 24, 19:04)

Just like in THE PRESENT MOMENT, space is also highlighted as an important notion in the talks to speak about the meditator, and is thus present in other CMs. For example, the space attributed to the meditator is also developed in the corpus at more fine-grained levels by means of SDs that characterise the TD MEDITATOR as more elaborated settings or particular kinds of places. Examples 16 and 17 illustrate CMs in which the TD MEDITATOR is represented as A MASS OF WATER, THE SKY, or a HOUSE (HOME). In 16, explicit reference to the SKY and the OCEAN introduces a perspective that -albeit not new because both SDs had been activated earlier in the talk- is overtly different from the topic at hand. This topic digression allows a conceptual parallelism to be established between part of the structure highlighted in the TD (MEDITATOR and their prototypical mental contents, namely THOUGHTS) and that of both SDs (SKY and CLOUDS on the one hand, and OCEAN and WAVES on the other) which invites the audience to reconsider, under this new light, the point -if any- of 'trying to stop thoughts'. In 17, MEDITATOR IS A HOME is realised implicitly through an indirect metaphor (a prototypical locus for non-deliberate uses). While no explicit marks of deliberateness can be found, HOME had also been used earlier in discourse, thereby echoing previous deliberate uses which endow the SD with enough relevance for this case also to be categorised as deliberate. In fact, 17 is the closing statement of the talk where the HOUSE scenario in which thoughts were pictured as children knocking at the meditators' door was activated (see example 3). 'Has a home' works thus as an attractor (Cameron \& Deignan, 2006) of all inferences established previously in the talk, including the emotional and attitudinal baggage that emerged in the 'children' metaphor, hence increasing the effects of the (take-home) message to conclude the talk.

(16) Many people think that meditation is about stopping thought, but the sky doesn't need to stop the clouds, the ocean doesn't need to stop its waves. We're not trying to stop thoughts: we're remembering the field, the wide-open space in which thoughts are allowed... (Foster, 2015, January 3, 4:45)

(17) That is the relief of just being the space in which every thought (however strange however fantastical, however seemingly negative), where every feeling (however intense, however unexpected, however uncomfortable), has a home. (Foster, 2016, May 19, 6:40)

Finally, it is also worth noting the change of perspective that is afforded by the negation of some of the components involved in examples like 15 and 16 (e.g. the idea that meditators are not actually meditators in 15 or that meditation is not about stopping thoughts in 16). This helps the speakers to highlight common preconceptions about the meditator and restructure potential misconceptions by adding more suitable configurations (e.g. the idea that meditators should rather be conceived of as the 'space for meditation' in 15, or that meditation is more about focussing on the space in which thoughts are allowed to exist in 16). As proposed in the introduction section, such processes of reconceptualisation can be achieved via metaphor. In example 18, for instance, the meditator is described as not embodying the emotion itself (i.e. to be sadness), but as the space for that emotion to exist. The example is illustrative of the direct metaphor formula A IS NOT B, BUT C (Cf. Bogetić, 2017), which facilitates the TD to be reconsidered in the light of the contrasting perspectives offered by different SDs. 
(18) You're letting sadness come back, if sadness wants to come back. Because you are not the sadness, you are the space for the sadness, the sky, the presence. (Foster, 2016, May $19,6: 02)$

DMs found in SDs like EMOTION, THOUGHT or LIFE EVENTS (see Table 4) are used in this fashion as corrective framing devices (Bogetić, 2017) helping to mark a distance between the meditator and phenomena of experience. Through these metaphors, speakers portray more vividly the idea that the meditator may experience particular kinds of emotions and thoughts (and may often be carried away by them) and that they may identify themselves at some points with some roles or identities in everyday life; but also that all of these (including our own conditionings from past experiences) must be brought to our awareness (via meditation practice) so that we can come to clearly discern that, ultimately, we are not that which we think, experience or do, but-according to the philosophy of the meditation masters- the PRESENCE or PURE CONSCIOUSNESS that allows these phenomena to exist.

On the whole, the varied assortment of SDs with which the meditator is addressed metaphorically in the corpus accounts for its representation as a complex, multifaceted entity. A predominant metaphorical image evokes the notion of space through a series of SDs activated several times in the corpus. Other SDs, however, are used only once (namely, the last six SDs in Table 4). Although less central, the latter are used deliberately in the talks to highlight other facets of the meditator and help the speakers to put their points across, thereby also contributing to construe a conceptualisation of the meditator that is closer to their own views while also stepping away from shallow cultural representations. Overall, the analysis suggests that the metaphorical characterisation of MEDITATOR is devised to disregard 'active' conceptions of the meditator as an agent that performs the meditative process (i.e. the commonplace conception of meditators by non-meditators) to frame it instead as a non-reactive space or presence for meditation to arise and flourish naturally.

\section{CONCLUSION}

The notion of meditation has been the object of scrutiny in Eastern religious traditions like Buddhism or Hinduism, where a wealth of treatises and classification systems can be found. In psychology, different types of meditative practices have been studied in terms of the mental and physiological processes involved, as well as their effects in different types of population and conditions (Dahl et al., 2015). In this context, meditation components have also been parameterised in constructs (e.g. non-reactivity, decentering, acceptance, compassion) that are measured with scientific precision (Cebolla et al., 2014). In the realm of spirituality, however, a rigorous classification and definition of meditation does not exist. As a result, the notion of meditation (let alone particular components) is much vaguer, and spiritual teachers often need to explain firstly what they understand by 'meditation' before telling their audience 'how to meditate'. In order to get rid of their audience's preconceptions about meditation, they often resort to popular models of experience (i.e. common representations of topics like thoughts, emotions, the meditator, etc.) and try to restructure their understanding by adding alternative perspectives. In this attempt, moreover, the three spiritual teachers analysed here make explicit their concern about bridging understanding and first-person experience (their view is that language may provide for understanding but, ultimately, meditators must go beyond linguistic and conceptual models of representation of experience, which are considered as limited or biased, to access real experience directly and tap into the true nature of reality). This may explain why their oral production is so rich in metaphors. By echoing 'popular' models of representation, conventional metaphors are useful in recruiting well-established shared knowledge structures to promote understanding; in contrast, more novel and creative uses seem 
especially helpful in introducing 'meditative-like' perspectives on the topic under discussion that do not necessarily match more widespread folk conceptions. The same concern may account for the variety of external areas of experience the speakers bring forth as metaphorical SDs to highlight particular aspects of the main topics of interest in their talks.

Apart from personification and objectification, prominent $\mathrm{CMs}$ in the corpus characterise the MEDITATOR as SPACIOUSNESS, as the PRESENCE and CONSCIOUSNESS where inner present-moment experience unfolds. Likewise, THE PRESENT MOMENT is represented as the SPACE where life unfolds; a space that includes the meditator's 'inner space' as well as any 'outer' phenomena surrounding the meditator. When the need arises to emphasise particular aspects of 'either' space in relation to the contents of that arise therein (these including THOUGHTS), more fine-grained SDs are elaborated, such as the OCEAN or HOUSE scenarios. Although they are addressed discursively as separate topics, this overlapping hints at a higherorder understanding of both spaces as merging in a single one, namely, a more transcendental field of consciousness where inner and outer phenomenological distinctions (and in fact any division established by our minds) become irrelevant.

The analysis presented here is based on a small corpus, but its findings provide initial evidence regarding variation and influence of some of the metaphorical models used across religious and secular (mindfulness) contexts. Some SDs found in Buddhist religious discourse (particularly those drawing on images from the realm of nature) are reused in spiritual-but-notreligious contexts to address the relationship between mental contents (mainly THOUGHTS) and the MEDITATOR. Likewise, the (GUEST) HOUSE scenario was found to permeate religious contexts in metaphorical representations of the MEDITATOR, as well as of THE PRESENT MOMENT. THOUGHTS, MEDITATOR, MEDITATION and EMOTION qualify as dominant TDs in both discourse contexts (Silvestre-López \& Navarro, 2017), which suggests that there may be concomitances worth analysing in further studies. In contrast, allusion to the temporal dimension (with a focus on THE PRESENT MOMENT), can only be found as a prominent topic in spiritual-but-not-religious and secular meditation discourse contexts. In the latter, emphasis is placed, via metaphor, on EMOTIONS, FEELINGS, THOUGHTS and the attitude of the meditator, but not on the MEDITATOR per se; this can be interpreted as a discursive reflection of the importance given, in mindfulness instruction contexts, to the quality of the attention to present-moment experience required to practice mindfulness meditation (Cebolla, García-Campayo \& Demarzo, 2014; Kabat-Zinn, 2003). Overall, the set of TDs and SDs in the discourse of mindfulness instructors seems to be more reduced -instructors have been found to use mainly objectification and personification metaphors to verbally handle mental and emotional processes during mindful practice (Silvestre-López, 2016). This hints that CMs may be more prolific in religious and spiritual contexts than in secular ones, perhaps due to the conceptual clarification efforts made by psychologists to parameterise meditative practice and its components into measurable constructs.

Regarding the functions of metaphor in discourse, due to the instructional nature of the talks, most metaphors share an underlying explanatory purpose. Some functions, mainly ideational and interpersonal, have been found to hold for different CMs related to the TDs THOUGHT, THE PRESENT MOMENT and MEDITATOR. Among them the use of DM stands out as a framing device to foster reconceptualisation of the TD -in some cases, like MEDITATOR, by establishing direct contrast between two competing SD representations. Similar functions have been identified in Buddhist discourse (Silvestre-López, 2019), where SDs typically evoke vivid imagery to foster understanding, often through reconceptualisation of the TD. Nonetheless, further research is needed to provide an exhaustive account of dominant metaphor functions across spiritual-religious-secular settings and, overall, to reveal explicit functions of DM in meditation discourse. 
On the whole, this paper has contributed to a growing number of studies embracing the dimensions of language, thought, and communication in the analysis of CM. While using small corpora has limitations concerning the generalisability of results, the bottom-up approach adopted here has provided for the identification not only of dominant metaphorical models in this kind of discourse, but also of all kinds of metaphors, without overlooking instances which might have gone unnoticed in a top-down analysis focussing on a pre-defined set of topics, types or tokens. In particular, this analysis favoured the identification of all DM instances by applying DMIP, especially those for which no obvious cues are provided in the surrounding text or immediate context and/or are triggered by the topic of the talks, induced by context, or even echo other extra-(con)textual factors like other talks by the same author or other spiritual teachers. The findings presented here support previous claims on the importance of grounding DM research in bottom-up analyses (Reijnierse et al., 2018), but these findings go beyond metaphor identification. For example, this approach has allowed the notion of SD granularity to be detected as an important distinguishing factor in NDM/DM use in spiritual-but-notreligious meditation discourse, but also as a necessary analytical component (in the shape of the book of SD codes developed inductively in this study) to trace fine-grained discursive developments of the CMs used by the meditation masters in the corpus. Notwithstanding this, research with larger meditation-related corpora and quantitative analyses -especially top-down surveys targeting the conceptual categories that underlie the set of TDs and SDs identified so far in bottom-up analyses like the abovementioned ones-is needed to set more comprehensive generalisations about the use of CM in contemplative practice discourse settings. Furthermore, comparing the use of particular CMs in meditation-specific and general corpora would also help to determine the extent to which the domains identified as prominent conceptual categories in the context of meditation are -if so- also relevant in more general contexts unrelated to meditation. This would provide further evidence concerning how common topics like, say, thoughts, emotions, feelings or the mind are modelled in discourse belonging to each context, thereby providing useful insight into how the 'popular' and 'meditative-like' models of representation of experience mentioned earlier in this section generally interact.

This paper has presented one of the first explorations into the study of metaphor in the discourse of contemplative practices as approached from a spiritual perspective. Its findings provide initial evidence of the main CMs used to frame knowledge about meditation in this kind of discourse, and hint at the existence of variation and influence in prominent CM use across religious and secular meditation discourse contexts (Cf. Silvestre-López, 2016, 2019; Silvestre-López \& Navarro, 2017). For example, the paper has illustrated how some metaphorical models from traditional religious spheres are perpetuated in spiritual-but-notreligious meditation discourse, despite the alleged more general trend in the spiritual-but-notreligious perspective to become disentangled and differentiated from traditionally institutionalised religious discourses (Schedneck, 2013; Wong \& Vinsky, 2009). Such findings suggest that more varied or stronger concomitances and influence pathways may exist across religious, spiritual-but-not-religious, and secular meditation settings. This opens a new line where further research will have to explore convergence-divergence patterns of CM use across different discourse contexts, and to trace potential influence pathways ${ }^{5}$ that, due to the growing global interest in mindfulness and meditation practice, may have already permeated geographical, cultural, and temporal boundaries. Beyond that, the question arises as to whether CMs are rendered differently in discourse (both in form and function) not only across different meditation settings, but also in different types of text or even genre. For example, the same CM used with the purpose of exemplifying a notion in a pedagogical talk or an introductory mindfulness course might also be used by the instructor as part of a guided meditation exercise

\footnotetext{
${ }^{5}$ That is, the influence route of a metaphorical model used previously in other cultural, philosophical, and/or religious contexts.
} 
to help to facilitate an experience (e.g. realising the nature of particular emotions, noticing judgements and thoughts, observing without intervening) or even to generate desirable attitudes in novel meditators during the practice (e.g. openness to experience, acceptance of unwanted thoughts, or even loving-kindness and compassion). Crucially, unveiling systematic patterns of metaphor use associated with intended purposes in different contemplative practice contexts may pave the way for a new series of applications of discourse analysis findings in other areas of personal, social and even professional practice. This is, in fact, one of the latest challenges for ongoing research in the field.

\section{ACKNOWLEDGEMENT}

I would like to thank the comments of the editor and the suggestions by both reviewers comments on earlier versions of this paper. This research was funded by the Conselleria d'Innovació, Universitats, Ciència i Societat Digital, Generalitat Valenciana, (GV/2019/101), and is also framed within the lines of research developed by the GReSCA research group at Universitat Jaume I (UJI-B2018-59).

\section{REFERENCES}

Albert, M. \& Hernàndez, G. M. (2014). Lo sagrado y la memoria: hacia una teoría sociológica de la religión. Revista Observaciones Filosóficas. Vol. 17. 1-20.

Bogetić, K. (2017). Language is a beautiful creature, not an old fridge: Direct metaphors as corrective framing devices. Metaphor and the Social World. Vol. 7(2), 190-220. https://doi.org/10.1075/msw.7.2.02bog

Bogetić, K. (2019). Discursive metaphorical frames in newspaper texts on language change. Metaphor and the Social World. Vol. 9(1), 1-31. https://doi.org/10.1075/msw.17013.bog

Cameron, L. \& Deignan, A. (2006). The Emergence of Metaphor in Discourse, Applied Linguistics. Vol. 27(4), 671-690. https://doi.org/10.1093/applin/aml032

Campos, D. \& Cebolla, A. (2016). Enseñar Mindfulness: Contextos de Instrucción y Pedagogía. Revista de Psicoterapia. Vol. 27(103), 103-118.

Cebolla, A., García-Campayo, J. \& Demarzo, M. (Eds.). (2014). Mindfulness y Ciencia. De la Tradición a la Modernidad. Madrid: Alianza.

Dahl, C.J., Lutz, A. \& Davidson, R. J. (2015). Reconstructing and deconstructing the self: cognitive mechanisms in meditation practice. Trends in Cognitive Sciences. Vol. 19(9), 515-523. https://doi.org/10.1016/j.tics.2015.07.001

Foster, J. [The Deepest Acceptance-Jeff Foster] (2012, January 26). How to accept this moment? [Video file]. Retrieved April 11, 2019 from https://www.youtube.com/watch?v=ArWw0y62FU4

Foster, J. [The Deepest Acceptance-Jeff Foster] (2012, May 24). "Who meditates?" A 20minute alternative guide to meditation. [Video file]. Retrieved April 11, 2019 from https://www.youtube.com/watch?v=XbQzZg0neKE

Foster, J. [The Deepest Acceptance-Jeff Foster] (2015, January 3). True meditation has no goal. [Video file]. Retrieved April 11, 2019 from https://www.youtube.com/watch?v=tZQshhxqQSs

Foster, J. [The Deepest Acceptance-Jeff Foster] (2015, March 27). You can't be 'in' the Now (or 'out' of it; you ARE the Now!) [Video file]. Retrieved April 11, 2019 from https://www.youtube.com/watch?v=rrbd6mHKV_E 
Foster, J. [The Deepest Acceptance-Jeff Foster] (2016, May 19). The Myth of 'Letting go'. [Video file]. Retrieved April 11, 2019 from https://www.youtube.com/watch?v=4BHvRkgqgLw

Fuller, R. C. (2001). Spiritual, but not Religious: Understanding Unchurched America. Oxford: Oxford University Press. https://doi.org/10.1093/0195146808.001.0001

Goatly, A. (2011). The Language of Metaphors (2nd ed.). New York: Routledge.

Kabat-Zinn, J. (2003). Mindfulness-based interventions in context: Past, present, and future. Clinical Psychology: Science and Practice. Vol. 10, 144-156. https://doi.org/10.1093/clipsy.bpg016

Kimmel, M. (2012). Optimizing the analysis of metaphor in discourse: how to make the most of qualitative software and find a good research design. Review of Cognitive Linguistics, Vol. 10(1), 1-48. https://doi.org/10.1075/rcl.10.1.01kim

Krishnamurti, J. [I Vinay] (2012, March 2). Saanen 7th Public Talk (July 25th, 1976). What is Meditation (Truth and Actuality). [Video file]. Retrieved April 11, 2019 from https://www.youtube.com/watch?v=8b9E9gz3yTE

Lakoff, G. (1993). The contemporary theory of metaphor. In A. Ortony (Ed.), Metaphor and Thought (2nd ed., pp. 202-251). Cambridge: Cambridge University Press.

Lakoff, G., Espenson, J. \& Schwartz, A. (1991). Master Metaphor List. Second draft copy. Technical report. Cognitive Linguistics Group, University of California Berkeley. Retrieved May 1, 2019 from http://cog-sci.berkeley.edu

Langacker, R. W. (2008). Cognitive Grammar: A Basic Introduction. New York: Oxford University Press.

Rajandran, K. (2017). From matter to spirit: metaphors of enlightenment in Bhagavad-gìtā. GEMA Online ${ }^{\circledR}$ Journal of Language Studies. Vol. 17(2), 163-176. http://doi.org/10.17576/gema-2017-1702-10

Reijnierse, W. G. (2017). The value of deliberate metaphor. LOT Dissertation Series, 469. Ph.D. thesis. Utretch: LOT. Retrieved from https://www.lotpublications.nl/Documents/469_fulltext.pdf

Reijnierse, W. G., Burgers, C., Krennmayr, T. \& Steen, G. J. (2018). DMIP: A method for identifying potentially deliberate metaphor in language use. Corpus Pragmatics. Vol. 2(2), 129-147. https://doi.org/10.1007/s41701-017-0026-7

Richardson, P. \& Mueller, C. (2019). Moving yet being still: exploring source domain reversal and force in explanations of enlightenment. Language and Cognition. Vol 11(2), 310339. https://doi.org./10.1017/langcog.2019.19

Schedneck, B. (2013). The decontexualization of Asian religious practices in the context of globalization. Journal for Cultural and Religious Theory. Vol. 12(3), 36-54.

Silvestre-López, A. J. (2016). The discourse of mindfulness: what language reveals about the mindfulness experience. In P. Ordóñez-López \& N. Edo-Marzà (Eds.). New Insights into the Analysis of Medical Discourse in Professional, Academic and Popular Settings (pp. 173-198). Bristol: Multilingual Matters.

Silvestre-López, A. J. (2019). Deliberate metaphors in Buddhist teachings about meditation. In I. Navarro-i-Ferrando (Ed.). Current Approaches to Metaphor Analysis in Discourse (pp. 205-234). Berlin, Boston: Mouton de Gruyter. https://doi.org/10.1515/9783110629460-010

Silvestre-López, A. J., \& Navarro, I. (2017). Metaphors in the conceptualization of meditative practices. Metaphor and the Social World. Vol. 7(1). 26-46. https://doi.org/10.1075/msw.7.1.03sil

Steen, G. J. (2011). The contemporary theory of metaphor-now new and improved! Review of Cognitive Linguistics. Vol. 9(1), 24-64. https://doi.org/10.1075/rcl.9.1.03ste 
Steen, G. J. (2015). Developing, testing and interpreting deliberate metaphor theory. Journal of Pragmatics. Vol. 90, 67-72. https://doi.org/10.1016\%2Fj.pragma.2015.03.013

Steen, G. J., Dorst, A. G., Herrmann, J. B., Kaal, A. A., Krennmayr, T. \& Pasma, T. (2010). A Method for Linguistic Letaphor Identification: From MIP to MIPVU. Amsterdam: John Benjamins. https://doi.org/10.1075/celcr.14

Tolle, E. (2009). What is meditation? Realizing the life that you are. [DVD]. Vancouver; Eckhart Teachings.

Wong, Y. \& Vinsky, J. (2009). Speaking from the margins: A critical reflection on the 'spiritual-but-not-religious' discourse in social work. British Journal of Social Work. Vol. 39, 1343-1359. https://doi.org/10.1093/bjsw/bcn032

\section{ABOUT THE AUTHOR}

Antonio-José Silvestre-López (European Ph.D. in Applied Linguistics) is an associate professor at Universitat Jaume I (Spain). His research interests concern the analysis of conceptual metaphor at the levels of language, thought and communication in different types of discourse, and their application in specialised areas of professional and educational practice. 